\title{
Iron: a Versatile Element to Produce Materials for Environmental Applications
}

\author{
Ana Paula C. Teixeira, ${ }^{*, a}$ Juliana C. Tristão, ${ }^{*, b}$ Maria H. Araujo, ${ }^{a}$ Luiz C. A. Oliveira, ${ }^{a}$ \\ Flávia C. C. Moura, ${ }^{a}$ José D. Ardisson, ${ }^{c}$ Camila C. Amorim ${ }^{d}$ and Rochel M. Lago ${ }^{* a}$ \\ ${ }^{a}$ Departamento de Química, Universidade Federal de Minas Gerais, 31270-901 Belo Horizonte-MG, Brazil \\ ${ }^{b}$ Universidade Federal de Viçosa, Rodovia LMG, 818, km 6, Campus Florestal, 35690-000 Florestal-MG, Brazil \\ 'Laboratório de Física Aplicada, Centro de Desenvolvimento da Tecnologia Nuclear, \\ 30123-970 Belo Horizonte-MG, Brazil \\ ${ }^{\mathrm{d}}$ Departamento de Engenharia Sanitária e Ambiental, Universidade Federal de Minas Gerais, \\ 31270-901 Belo Horizonte-MG, Brazil
}

Ferro é um elemento versátil que forma várias fases com diferentes estados de oxidação e estruturas, tais como $\mathrm{Fe}^{0}, \mathrm{FeO}, \mathrm{Fe}_{3} \mathrm{O}_{4}, \gamma-\mathrm{Fe}_{2} \mathrm{O}_{3}, \alpha-\mathrm{Fe}_{2} \mathrm{O}_{3}$ e $\mathrm{FeOOH}$. Todas estas fases têm propriedades físico-químicas únicas que podem ser usadas para diferentes aplicações. Neste trabalho, descreve-se o uso de diferentes compostos de ferro, sintéticos e também naturais ou de rejeitos, em aplicações ambientais e tecnológicas. Duas áreas principais de pesquisa são descritas. A primeira é relacionada às estratégias para aumentar a reatividade de fases de ferro pela formação de compósitos $\mathrm{Fe}^{0} / \mathrm{Fe}$ óxido e pela introdução de novos metais na estrutura de óxidos de ferro para promover novas reações superficiais. A segunda área de pesquisa é o uso das propriedades magnéticas de algumas fases de ferro para produzir materiais magnéticos versáteis com aplicações focadas em adsorção, catálise e emulsões.

Iron is a versatile element forming several phases with different oxidation states and structures, such as $\mathrm{Fe}^{0}, \mathrm{FeO}, \mathrm{Fe}_{3} \mathrm{O}_{4}, \gamma-\mathrm{Fe}_{2} \mathrm{O}_{3}, \alpha-\mathrm{Fe}_{2} \mathrm{O}_{3}$ and $\mathrm{FeOOH}$. All these phases have unique physicochemical properties which can be used for different applications. In this work, it is described the use of different iron compounds, synthetic and also from natural and waste sources, in environmental and technological applications. Two main research areas are described. The first one is related to strategies to increase the reactivity of Fe phases, mainly by the formation of $\mathrm{Fe}^{0}$ /iron oxide composites and by the introduction of new metals in the iron oxide structure to promote new surface reactions. The second area is the use of the magnetic properties of some iron phases to produce versatile magnetic materials with focus in adsorption, catalysis and emulsions.

Keywords: iron, environmental applications, magnetite, composites

\section{Introduction}

Iron is a versatile element and can form several phases with different oxidation states and structures, such as $\mathrm{Fe}^{0}$, $\mathrm{FeO}$ (wüstite), $\mathrm{Fe}_{3} \mathrm{O}_{4}$ (magnetite), $\gamma-\mathrm{Fe}_{2} \mathrm{O}_{3}$ (maghemite), $\alpha-\mathrm{Fe}_{2} \mathrm{O}_{3}$ (hematite) and $\mathrm{FeOOH}$ (oxyhydroxy) (equation 1).

$\mathrm{Fe}^{0} \rightarrow \mathrm{FeO} \rightarrow \mathrm{Fe}_{3} \mathrm{O}_{4} \rightarrow \gamma-\mathrm{Fe}_{2} \mathrm{O}_{3} \rightarrow \alpha-\mathrm{Fe}_{2} \mathrm{O}_{3} \rightarrow \mathrm{FeOOH}$

All these phases have unique physicochemical properties which can be used for a wide range of technological and

*e-mail: rochel@ufmg.br, anapct@ufmg.br, juliana@ufv.br environmental applications. Most of the important chemistry of these iron phases has been very well described in the classical book of Cornel and Schwertmann. ${ }^{1}$

Besides all the uses of Fe metal in the steel industry, zero valent iron has been extensively investigated for environmental remediation due to its reducing properties. Several contaminants such as organochloro compounds, nitrates, dyes, $\mathrm{Cr}(\mathrm{VI})$ and arsenic species can be treated by simple reduction with $\mathrm{Fe}^{0}$.

Magnetite $\left(\mathrm{Fe}_{3} \mathrm{O}_{4}\right)$ is an inverse spinel structured oxide with several important features for environmental applications, e.g., (i) it is magnetic, (ii) it contains $\mathrm{Fe}^{2+}$ in the structure which is an important electron donor, and 
(iii) the octahedral site in the magnetite structure can easily accommodate both $\mathrm{Fe}^{2+}$ and $\mathrm{Fe}^{3+}$, producing a very interesting redox chemistry within the solid structure (Figure 1). If the $\mathrm{Fe}^{2+}$ is completely oxidized, magnetite is converted to the magnetic maghemite $\left(\gamma-\mathrm{Fe}_{2} \mathrm{O}_{3}\right)$ with the same spinel structure. At temperatures higher than $500{ }^{\circ} \mathrm{C}$, maghemite is converted to the hexagonal hematite $\left(\alpha-\mathrm{Fe}_{2} \mathrm{O}_{3}\right)$ with the loss of the magnetic properties. Also, different forms of iron oxy/hydroxyl $\mathrm{FeO}(\mathrm{OH})$ can be prepared such as goethite, lepidocrocite and akaganeite.

Other important features for the industrial and environmental application of iron compounds are the low cost, low toxicity and relatively good stability of the $\mathrm{Fe}$ phases. Iron is a very abundant element available in nature, mainly as magnetite $\left(\mathrm{Fe}_{3} \mathrm{O}_{4}\right)$, maghemite $\left(\gamma-\mathrm{Fe}_{2} \mathrm{O}_{3}\right)$ and hematite $\left(\alpha-\mathrm{Fe}_{2} \mathrm{O}_{3}\right)$. Other very interesting sources of iron are the wastes produced in large quantities by different industrial activities such as aluminum production (red mud), foundry (sand waste) and steel production.

In this account, it is described our efforts to use different iron compounds, e.g., synthetic and also from natural and waste sources, in environmental and technological applications. Two main research areas are described. The first one is related to strategies to increase the reactivity of Fe phases, mainly (i) by the formation of $\mathrm{Fe}^{0} / \mathrm{Fe}$ oxide composites and (ii) by the introduction of new metals in the iron oxide structure to promote new surface reactions. The second area is the use of the magnetic properties of some iron phases to produce versatile magnetic composites with focus in adsorption, catalysis and emulsions.

\section{Application of Iron Oxides and Metal for Waste Water Treatment}

\section{Use of iron phases and heterogeneous Fenton systems}

The Fenton reagent, a mixture of $\mathrm{Fe}^{2+}$ and $\mathrm{H}_{2} \mathrm{O}_{2}$, is one of the most efficient systems to destroy organic contaminants in water. The efficiency of the Fenton reagent is due to the in situ generation of highly oxidative species, i.e., hydroxyl radicals, according to the simplified process (equation 2):

$$
\mathrm{Fe}^{2+}(\mathrm{aq})+\mathrm{H}_{2} \mathrm{O}_{2} \rightarrow \mathrm{Fe}^{3+}(\mathrm{aq})+\mathrm{OH}^{-}+\mathrm{OH}^{\cdot}
$$

The Fenton reaction operates at an optimum $\mathrm{pH}$ of 3 and requires stoichiometric amounts of $\mathrm{Fe}^{2+}$. After the process, the effluent must be neutralized generating significant amounts of iron hydroxide sludge, which is an important drawback of the process due to disposal problems. ${ }^{2,3}$
Active heterogeneous Fenton systems, in which soluble $\mathrm{Fe}^{2+}$ does not precipitate since it is replaced by Fecontaining solids, show several very interesting advantages over the classical homogeneous reaction, such as operation at near neutral $\mathrm{pH}$, no sludge formation and the possibility to recycle the iron promoter. Some of the irons containing solids that were investigated were goethite, hematite, clay minerals, iron hydroxide and iron supported on silica and on alumina. ${ }^{4-9}$ However, these iron promoters showed low activities or strong iron leaching due to low $\mathrm{pH}$ which produced mainly homogeneous reactions.

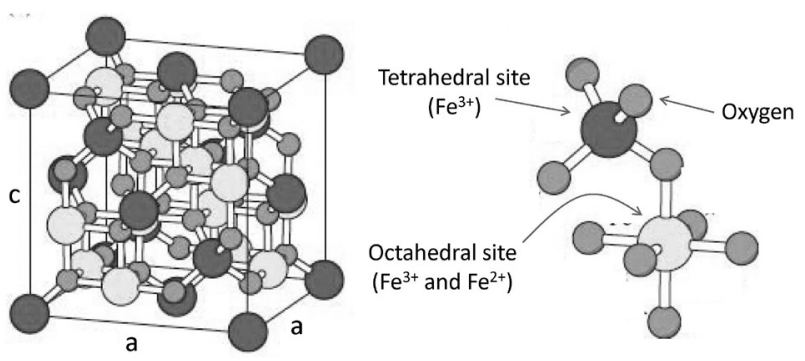

Figure 1. Representation of the crystalline structure of magnetite (adapted from reference 10).

Our group has been investigating the use of the inverse spinel magnetite, $\mathrm{Fe}_{3} \mathrm{O}_{4}$, for the Fenton reaction due to its remarkable features, e.g., (i) it contains $\mathrm{Fe}^{2+}$ in the structure which should play an important role as an electron donor to initiate the Fenton process according to the classical Haber-Weiss mechanism (equation 2), and (ii) the octahedral site in the magnetite structure can easily accommodate both $\mathrm{Fe}^{2+}$ and $\mathrm{Fe}^{3+}$, producing a very dynamic redox chemistry within the solid structure.

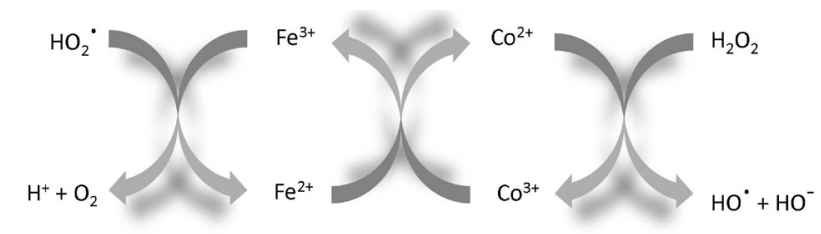

Figure 2. Proposed mechanism for the participation of Co in the Fenton reaction.

The spinel structure also allows isostructural substitution of iron by different transition metals which can completely modify the physicochemical properties of the solid to produce more active systems. For example, the introduction on $\mathrm{Mn}$ and $\mathrm{Co}$ to produce $\mathrm{Fe}_{3-\mathrm{x}} \mathrm{Mn}_{\mathrm{x}} \mathrm{O}_{4}$ and $\mathrm{Fe}_{3-\mathrm{x}} \mathrm{Co}_{\mathrm{x}} \mathrm{O}_{4}$ resulted in a remarkable increase in the activity for $\mathrm{H}_{2} \mathrm{O}_{2}$ decomposition and the oxidation of the organic molecules. The reaction apparently takes place via radical species generated by $\mathrm{Fe}^{2+}, \mathrm{Co}^{2+}$ and $\mathrm{Mn}^{2+}$ (Figure 2). The high activity has been discussed in terms of a thermodynamically 
favorable regenerative reduction of $\mathrm{Co}^{3+}$ and $\mathrm{Mn}^{3+}$ by $\mathrm{Fe}^{2+}$ by an electron transfer within the semiconductor oxide. ${ }^{11,12}$

Also, chromium was introduced in the magnetite structure to produce a $\mathrm{Cr}-\mathrm{Fe}$ spinel active heterogeneous Fenton system. The presence of chromium also strongly increased the activity for the Fenton chemistry. It is proposed that this higher activity is related to the coupling of the redox pairs $\mathrm{Fe}^{3+} / \mathrm{Fe}^{2+}$ with $\mathrm{Cr}^{2+} / \mathrm{Cr}^{3+}$, which can regenerate the Fenton active specie $\mathrm{Fe}^{2+}$ more efficiently. ${ }^{11,12}$

The use of $\mathrm{Fe}^{0}$ to promote the Fenton reaction can be more efficient since the metal can potentially participate in the reaction with $3 \mathrm{e}^{-}$whereas $\mathrm{Fe}^{2+}$ can donate only $1 \mathrm{e}^{-}$. However, due to kinetic limitations, $\mathrm{Fe}^{0}$ alone is not active for the Fenton reaction at $\mathrm{pH} 7 \cdot{ }^{13}$ Some of the works developed in our group showed that the combination of $\mathrm{Fe}^{0}$ with $\mathrm{Fe}_{3} \mathrm{O}_{4}$ by a metal-oxide interface produces very active Fenton systems. The understanding of these interface phenomena and the development of processes to increase the electron transfer rate from the iron compounds to the reaction medium is of great interest in order to improve the efficiency and to widen the application of these systems in environmental remediation processes. ${ }^{3}$ For example, the combination of $\mathrm{Fe}_{3} \mathrm{O}_{4}$ with $\mathrm{Fe}^{0}$ metal by simple mechanical grinding showed remarkable increase in the activity for the Fenton reaction. ${ }^{13}$ Transmission electron microscopy (TEM) studies showed the formation of a nanocomposite with evident interface between the $\mathrm{Fe}_{3} \mathrm{O}_{4}$ and $\mathrm{Fe}^{0}$ particles (Figure 3).

This result was discussed in terms of an electron transfer mechanism from $\mathrm{Fe}^{0}$ to $\mathrm{Fe}^{3+}$ surf during the Fenton reaction to regenerate the $\mathrm{Fe}^{2+}{ }_{\text {surf }}$ active species (Figure 4). ${ }^{13,14}$

The mechanistic details studied by electrospray ionization mass spectrometry (ESI-MS) confirmed the

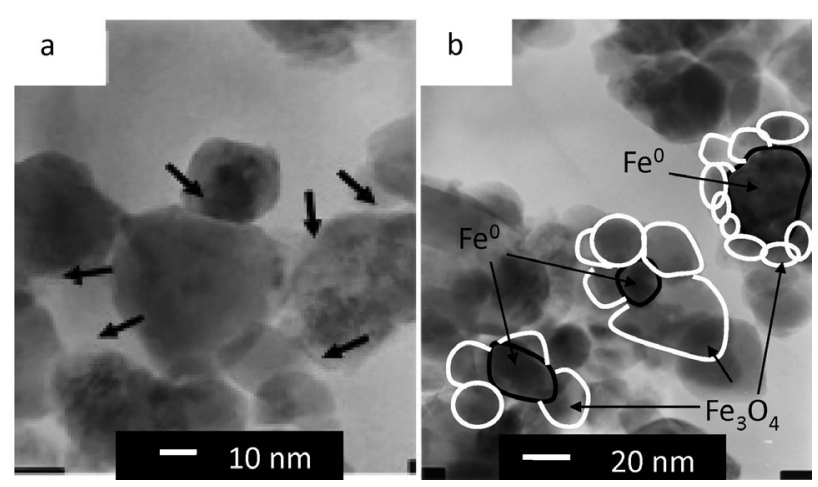

Figure 3. HRTEM image of the manually ground mixture $\mathrm{Fe}^{0}$ and $\mathrm{Fe}_{3} \mathrm{O}_{4}$ (a) arrows indicate interfaces between particles, (b) $\mathrm{Fe}^{0}$ surrounded by $\mathrm{Fe}_{3} \mathrm{O}_{4}$ particles (adapted from reference 14).

formation of $\mathrm{OH}$ radicals by the various hydroxylated intermediates. $^{15}$

Reactive systems are also produced by the mechanical grinding and thermal treatment of $\mathrm{Fe}^{0} / \alpha-\mathrm{Fe}_{2} \mathrm{O}_{3}$ and $\mathrm{Fe}^{0} / \gamma-\mathrm{Fe}_{2} \mathrm{O}_{3}$, however with much lower activity towards $\mathrm{H}_{2} \mathrm{O}_{2}$ compared with $\mathrm{Fe}^{0} / \mathrm{Fe}_{3} \mathrm{O}_{4}$ mixtures. ${ }^{3}$

Iron metal was also mixed with perovskite $\left(\mathrm{Fe}^{0} / \mathrm{LaMnO}_{3}\right)$ and used as catalysts in the Fenton reaction. ${ }^{16,17} \mathrm{LaMnO}_{3}$ can transfer oxygen to $\mathrm{Fe}^{0}$ by an interface reaction producing a partially reduced perovskite $\mathrm{LaMnO}_{3-\delta}$ and highly dispersed iron oxides, mainly $\mathrm{Fe}_{3} \mathrm{O}_{4}$, on the $\mathrm{Fe}^{0}$ surface (Figure 5). As the mixtures $\mathrm{Fe}^{0} / \mathrm{LaMnO}_{3}$ are treated at 200,400 and $600{ }^{\circ} \mathrm{C}$, the reactivity towards $\mathrm{H}_{2} \mathrm{O}_{2}$ decomposition decreases, whereas the activity for the oxidation of methylene blue increases. These results have been discussed in terms of a decrease on the concentration of $\mathrm{Mn}^{4+}{ }_{\text {surf }}$ and $\mathrm{Mn}^{3+}{ }_{\text {surf }}$ (active for $\mathrm{H}_{2} \mathrm{O}_{2}$ decomposition) with an increase on the $\mathrm{Mn}^{2+}$ surf and $\mathrm{Fe}^{2+}{ }_{\text {surf }}$ species, active for the Fenton reaction.

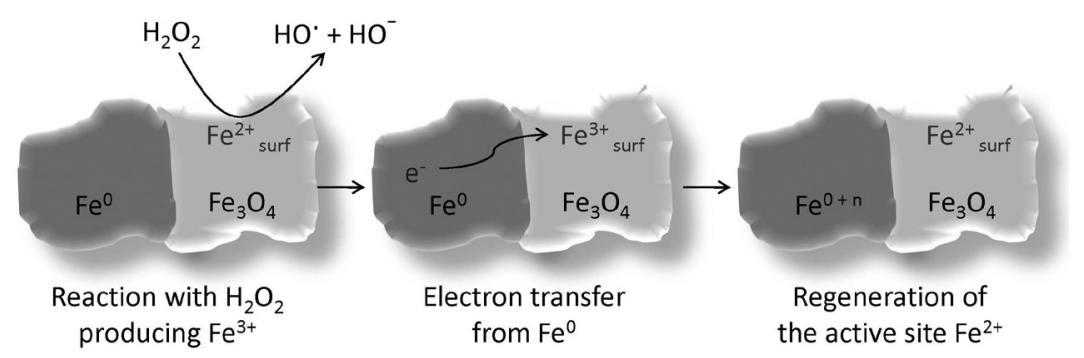

Figure 4. Schematic representation of the electron transfer from $\mathrm{Fe}^{0}$ to $\mathrm{Fe}^{3+}{ }_{\text {magnetite }}$ to regenerate $\mathrm{Fe}^{2+}$ surf (adapted from reference 13).

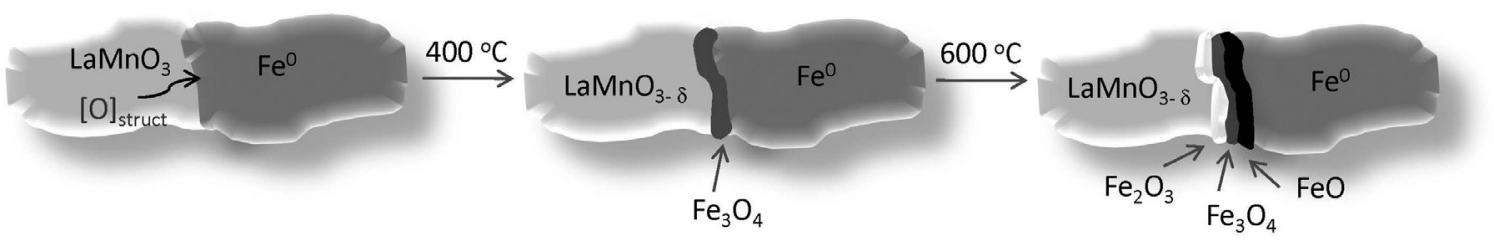

Figure 5. Scheme for the oxygen transfer from $\mathrm{LaMnO}_{3}$ to $\mathrm{Fe}^{0}$, forming different iron oxide phases (adapted from reference 18). 


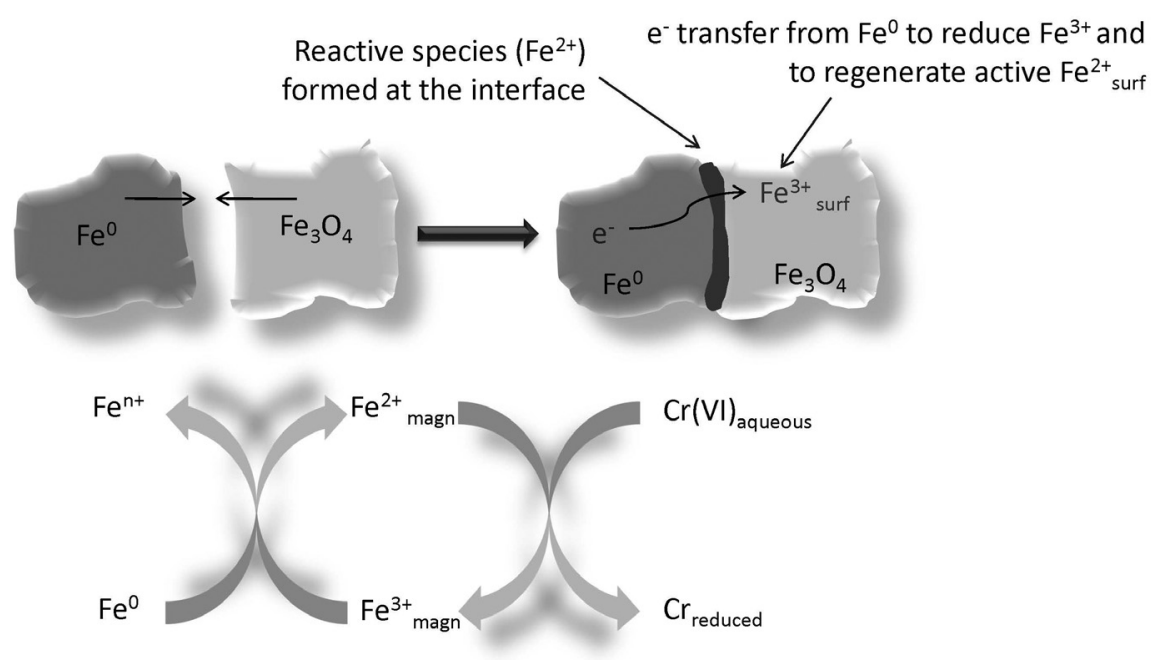

Figure 6. Schematic representation of the effects of mechanical alloying of $\mathrm{Fe}^{0}$ and $\mathrm{Fe}_{3} \mathrm{O}_{4}$ and a proposed reaction cycle (adapted from reference 14).

Use of iron phases for the reduction of $\mathrm{Cr}(\mathrm{VI})$ contaminants

The reduction of $\mathrm{Cr}(\mathrm{VI})$ to $\mathrm{Cr}(\mathrm{III})$ is a basic measure for groundwater remediation processes. Chromium(VI) compounds are contaminants of special concern due to carcinogenic and mutagenic activities. ${ }^{18}$ In the environment $\mathrm{Cr}(\mathrm{VI})$ comes most from industrial activities, e.g., in electroplating, leather tanning, pulp production, ore and petroleum refining processes, and from the high mobility of their oxyanions, e.g., $\mathrm{CrO}_{4}{ }^{2-}$ and $\mathrm{Cr}_{2} \mathrm{O}_{7}{ }_{7}^{2-}$ in water. ${ }^{19}$

Iron metal has been intensively investigated as $\mathrm{Cr}(\mathrm{VI})$ reducing agent. ${ }^{18,20,21}$ During this reaction, metallic iron is oxidized to $\mathrm{Fe}(\mathrm{III})$ while $\mathrm{Cr}(\mathrm{VI})$ is reduced to $\mathrm{Cr}(\mathrm{III})$, forming insoluble hydroxides. However, under environmental conditions, metallic iron shows a kinetic limitation with low reaction rates and rapid deactivation due to passivation of the metallic surface. ${ }^{22}$

Our group has found that $\mathrm{Fe}^{0} / \mathrm{Fe}_{3} \mathrm{O}_{4}$ composites produced by simple grinding mixtures showed much higher efficiency to reduce $\mathrm{Cr}(\mathrm{VI})$ compared to the $\mathrm{Fe}$ and magnetite phases isolated..$^{13,14,22-24}$ The reduction mechanism was discussed similar to the Fenton reaction, in which the $\mathrm{Fe}^{2+}$ oct (magnetite) acts as a reducing site producing the oxidized $\mathrm{Fe}^{3+}$ and the reduced $\mathrm{Cr}$ species. The $\mathrm{Fe}^{3+}{ }_{\text {oct }}$ can then be easily reduced back to $\mathrm{Fe}^{2+}{ }_{\text {oct }}$ with no structural constraint by the thermodynamically favorable electron transfer from $\mathrm{Fe}^{0}$ via the metal-oxide interface (Figure 6).

Another approach to produce a more efficient system for the reduction of $\mathrm{Cr}(\mathrm{VI})$ was to create highly dispersed Fe phases on the surface of activated carbon. ${ }^{23}$ These Fe/AC composites show some innovative aspects: $(i)$ the high surface area carbon support significantly increases the amount of reactive Fe-bearing chemical species,

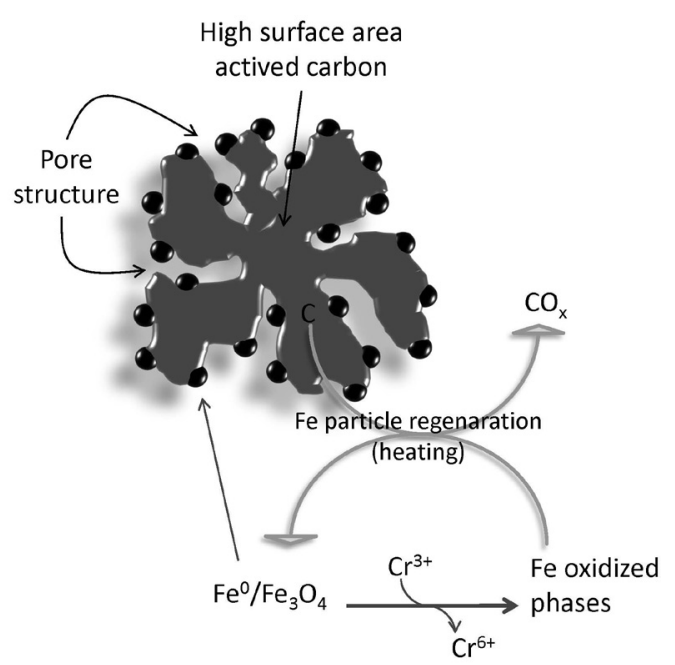

Figure 7. Schematic representation of the Fe phases on the surface of activated carbon and the process of $\mathrm{Cr}$ reduction and $\mathrm{Fe}$ oxidized phase regenerations.

dispersed as very small particles, (ii) after deactivation, the oxidized iron in the composite can be regenerated by a simple thermal treatment in which $\mathrm{Fe}^{3+}$ species react with carbon to regenerate the reduced active phases $\mathrm{Fe}^{0}$ and $\mathrm{Fe}_{3} \mathrm{O}_{4}$ (Figure 7).

Another novel approach to produce reduced active $\mathrm{Fe}$ phases was to use tar, a well-known waste from the charcoal industry, for the reduction of $\mathrm{Fe}_{2} \mathrm{O}_{3} \cdot{ }^{24}$ Upon thermal treatment, tar decomposes on the iron oxide $\mathrm{Fe}_{2} \mathrm{O}_{3}$ surface to produce elemental carbon, which readily reacts with $\mathrm{Fe}^{3+}$ to produce reduced $\mathrm{Fe}$ species (Figure 8).

After use and deactivation during $\mathrm{Cr}(\mathrm{VI})$ reduction, the oxidized iron in the composite can be easily regenerated by simple thermal treatment. In this treatment, $\mathrm{Fe}^{3+}$ species react with carbon to regenerate the initially active mixture of $\mathrm{Fe}^{0}$ and $\mathrm{Fe}_{3} \mathrm{O}_{4}$. 


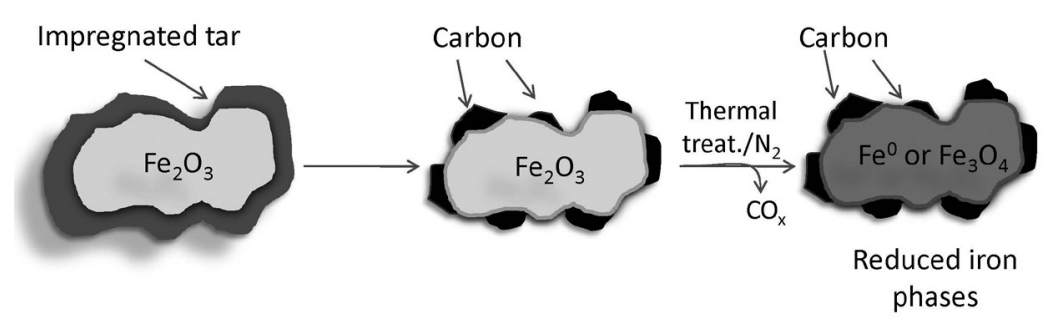

Figure 8. Schematic representation of the reduced Fe/carbon composites prepared from tar and $\mathrm{Fe}_{2} \mathrm{O}_{3}$ (adapted from reference 24).

\section{Application of Iron Phases to Produce Magnetic Materials as Adsorbents and Catalyst Support}

Several iron phases such as $\mathrm{Fe}^{0}, \mathrm{Fe}_{3} \mathrm{O}_{4}$ and $\gamma-\mathrm{Fe}_{2} \mathrm{O}_{3}$ (maghemite) show magnetic properties that can be used to produce magnetic materials. Some works in the literature have proposed the direct use of these iron phases as magnetic adsorbent for contaminants from aqueous or gaseous effluents. ${ }^{25-27}$ However, very low surface area or small adsorption capacities strongly limit their application. Some of the works in our group have been directed to prepare low cost efficient magnetic adsorbents by combining the adsorption properties of some materials with the magnetic properties of iron phases.

Activated carbon is an excellent adsorbent, especially for organic molecules and for some inorganic species. Activated carbon has high surface area and porous structure, high adsorption capacity and can be easily functionalized and used as an efficient adsorbent for heavy metal contaminants. ${ }^{28}$ The combination of magnetic iron phases with activated carbon offers an attractive and inexpensive option for the removal of different contaminants from water, such as pesticides, phenols and chlorophenols. ${ }^{29-32}$ Magnetic composites of activated carbon/iron oxide were prepared with several weight ratios of $2: 1,1.5: 1$ and $1: 1$ and used for the adsorption of volatile organic compounds (VOCs) such as chloroform, phenol, chlorobenzene and dyes from aqueous solution. ${ }^{29,30}$ The composites showed that the presence of the magnetic iron oxide did not affect the adsorption capacity of the activated carbon.

Natural clays are low-cost and readily available materials functioning as excellent cation exchangers, which have often been used to adsorb metallic contaminants. The adsorption capacity of clays results from a relatively high surface area and a net negative charge on their structure, which attracts and holds cations such as heavy metals. Bentoniteiron oxide magnetic composites have been produced by simple co-precipitation method and showed high adsorption capacities for the $\mathrm{Ni}^{2+}, \mathrm{Cu}^{2+}, \mathrm{Cd}^{2+}$ and $\mathrm{Zn}^{2+}$ in aqueous solution in the range 40-75 mmol of $\mathrm{M}^{2+} \mathrm{g}^{-1}$ of composite. ${ }^{33}$
Expanded or exfoliated vermiculite clay is an extremely interesting material with low cost a highly developed porous structure. This exfoliated mineral has been reported in some studies as effective to remove spilled oil from the water surface due to the strong capillary action of the slit shaped pores. ${ }^{34,35}$ Magnetic composites based on expanded vermiculite and iron were combined to prepare floating materials on water, being used to remove spilled oil contaminants. ${ }^{36}$ These magnetic materials have been coated/hydrophobized with polymers such as epoxy resin and polystyrene improving their oil removal capacity (Figure 9).

These composites showed several advantages over the simply exfoliated vermiculite: (i) they are magnetic and can be removed from the application medium by a simple magnetic separation procedure, (ii) the hydrophobization produced a strong increase in the oil adsorption/absorption capacity, (iii) the hydrophobization strongly increased the chemical resistance of the composites towards very acidic medium, and (iv) the hydrophobization strongly improved the mechanical resistance of the vermiculite, avoiding the delamination process and resulting in a completely floatable composite.

\section{Magnetic nanostructured composites based on carbon} coated iron phases

Iron magnetic particles can be coated with a protective layer of different materials to improve their stability and to introduce new surface properties and functionalities. Carbon is a versatile coating material due to its chemical stability, biocompatibility, possibility of surface modification and pore creation. In general, carbon coating processes are relatively complex, demanding special precursors and producing relatively low yields. ${ }^{37,38}$

Our group has been investigating the production of carbon coating by a combined reduction/CVD (chemical vapor deposition) process in which iron is first reduced to form magnetic particles followed by carbon deposition. Different carbon sources such as $\mathrm{CH}_{4}, \mathrm{C}_{2} \mathrm{H}_{4}$ and $\mathrm{CO}$ have been investigated. ${ }^{39}$ The combined reduction/CVD process using methane and hematite is a versatile, technically 


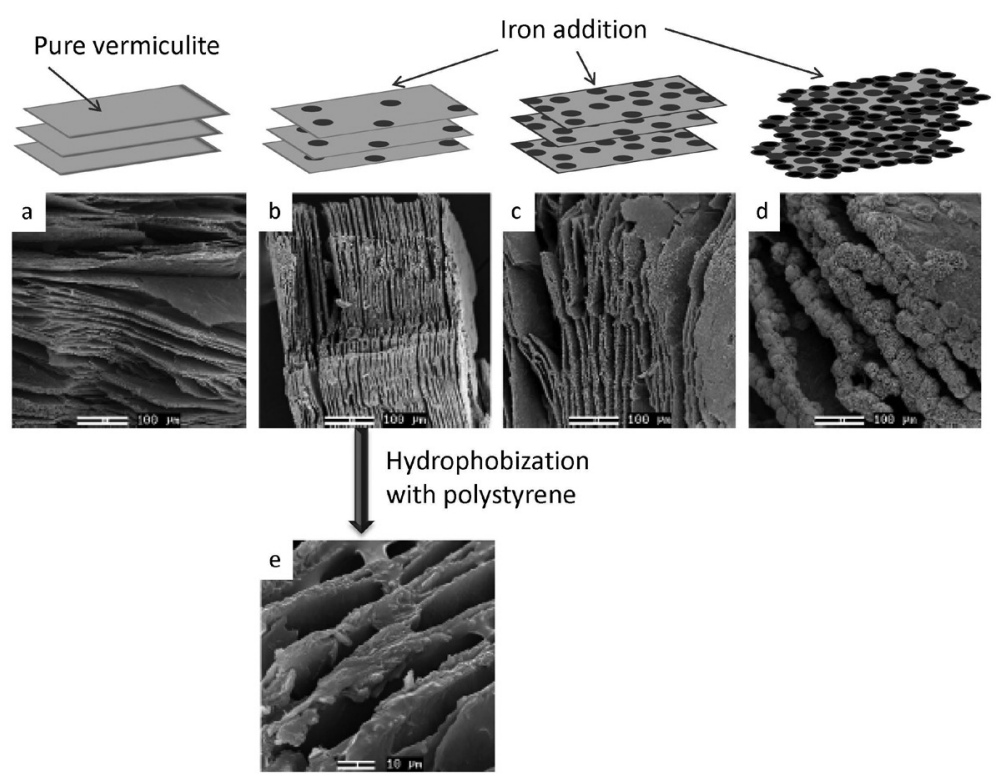

Figure 9. SEM images of the composites with expanded vermiculite (EV) and different iron content: (a) Fe0.0/EV, (b) Fe0.1/EV, (c) Fe1.5/EV and (d) Fe3.0/EV. The hydrophobized composite with polystyrene coated Fe0.1/EV: (e) Fe0.1/EV/PS1.0 (adapted from reference 36).

simple and low cost method to produce carbon coated $\mathrm{Fe}_{3} \mathrm{O}_{4}$ particles. ${ }^{40,41}$ In this process, methane reduces $\mathrm{Fe}_{2} \mathrm{O}_{3}$ with very good selectivity to $\mathrm{Fe}_{3} \mathrm{O}_{4}$ magnetic nuclei and leads to an amorphous carbon deposition by a CVD reaction (Figure 10).

This technically simple method can use as precursor different iron containing materials, such as synthetic $\left(\mathrm{Fe}_{2} \mathrm{O}_{3}, \mathrm{Fe}_{3} \mathrm{O}_{4}, \mathrm{FeOOH}\right.$, etc. $)$ and naturally occurring iron oxides or even iron containing wastes (e.g., red mud and mining waste). ${ }^{42}$

If ethanol is used as the reducing agent and carbon source, hematite is reduced to Fe metal and carbide and large amounts of carbon nanotubes (CNTs) are formed (Figure 11). These magnetic coated particles were used as adsorbent of organic compounds, e.g., methylene blue and chlorobenzene, and for the production of a magnetic recyclable supported $\mathrm{Pd}$ catalyst, as hydrogenation reactions (Figure 12). ${ }^{40-43}$

An innovative approach to produce magnetic nanoparticles based on iron cores encapsulated by a high surface area carbon was produced using $\mathrm{Fe}^{3+}$

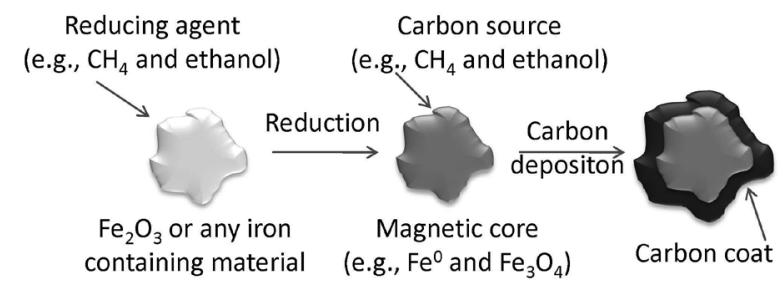

Figure 10. Schematic representation of the reduction of $\mathrm{Fe}_{2} \mathrm{O}_{3}$ and carbon coating (adapted from reference 40).
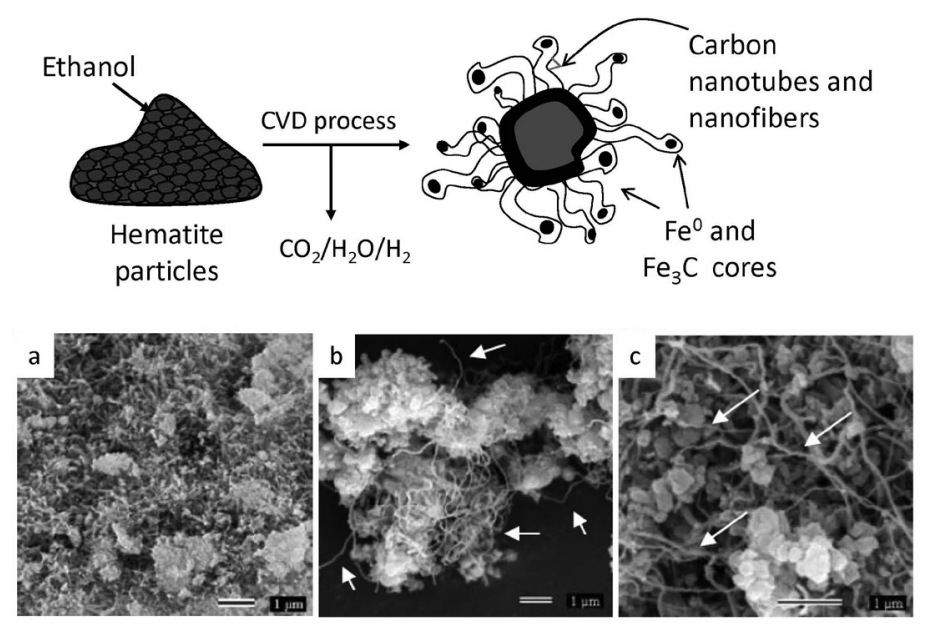

Figure 11. Scheme for the magnetic carbon nanotubes and nanofiber productions using ethanol and SEM images of the hematite before (a) and after reaction with ethanol at $800{ }^{\circ} \mathrm{C} \mathrm{(b} \mathrm{and} \mathrm{c)} \mathrm{(adapted} \mathrm{from} \mathrm{reference} \mathrm{43).}$ 


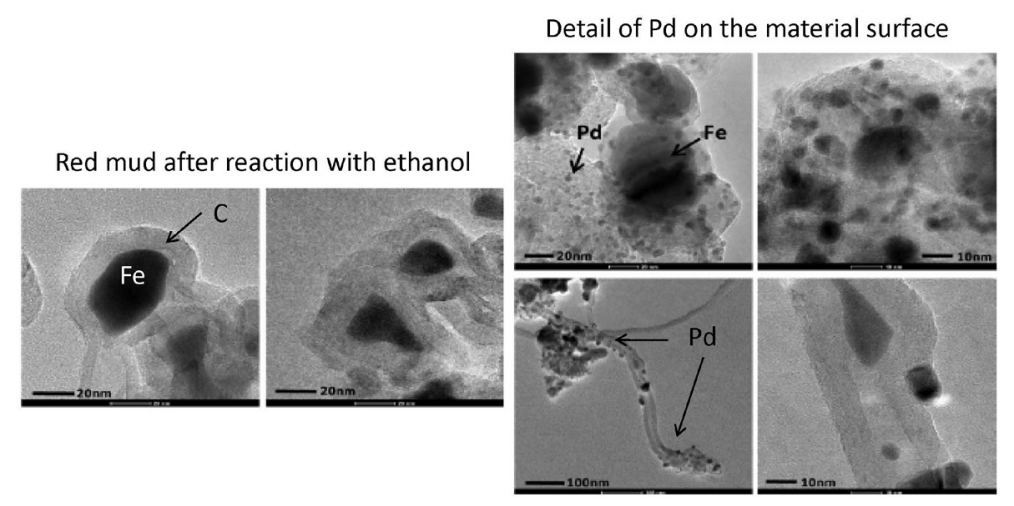

Figure 12. TEM images of red mud after reaction with ethanol at $700{ }^{\circ} \mathrm{C}$ without and with $5 \%$ of metallic palladium on the surface (adapted from reference 42 ).

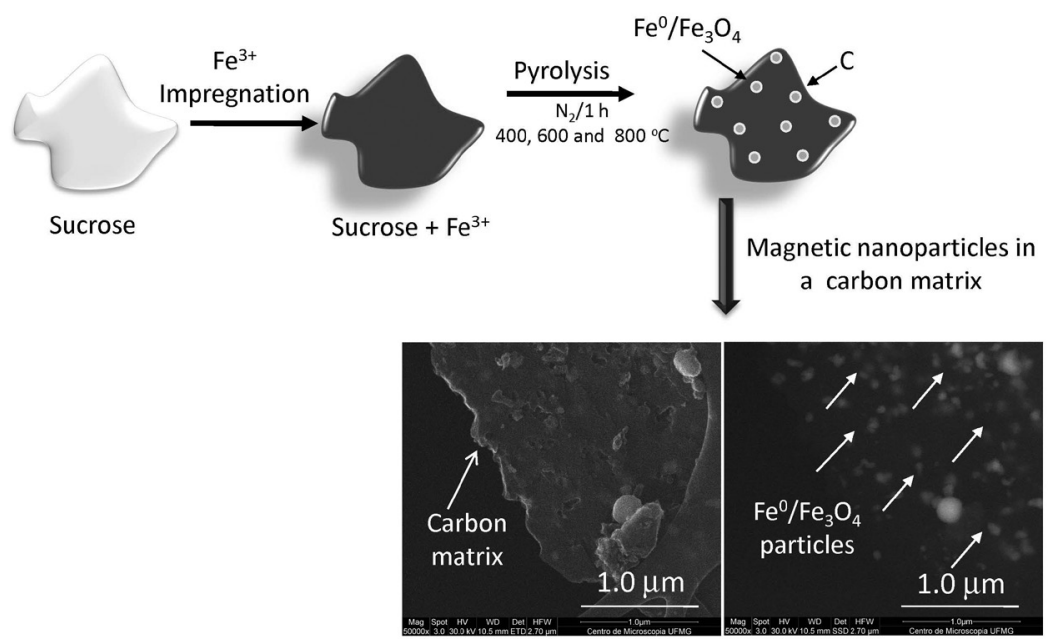

Figure 13. Scheme for magnetic nanoparticles formation by simultaneous reduction/pyrolysis process using sucrose and SEM images of iron particles in a carbonaceous matrix after pyrolysis of $8 \%$ iron in sucrose at $800{ }^{\circ} \mathrm{C}$ (adapted from reference 44).

ions and sucrose as a carbon source and reducing agent. In this process, first $\mathrm{Fe}^{3+}$ ions are solubilized in aqueous sucrose and upon thermal decomposition the iron is reduced to form magnetic particles surrounded by a nanometric layer of more organized graphitic carbon entrapped in an amorphous carbonaceous matrix (Figure 13) ${ }^{44}$ Studies of these materials as Pd catalysts support in hydrogenation reactions showed promising results with the full conversion of the substrate 1,5-COD (1,5-cyclooctadiene).

\section{Use of Iron to Produce Amphiphilic Magnetic Nanostructured Particles}

Amphiphilic synthesis

An important and innovative application of iron compounds developed in our group is on the production of amphiphilic composites. ${ }^{45-48}$ These amphiphilic materials are composed of a ceramic matrix (providing the hydrophilic surface) containing carbon nanostructures (responsible for the hydrophobic properties) and magnetic iron cores coated with carbon to produce the magnetic properties of the composite (Figure 14).

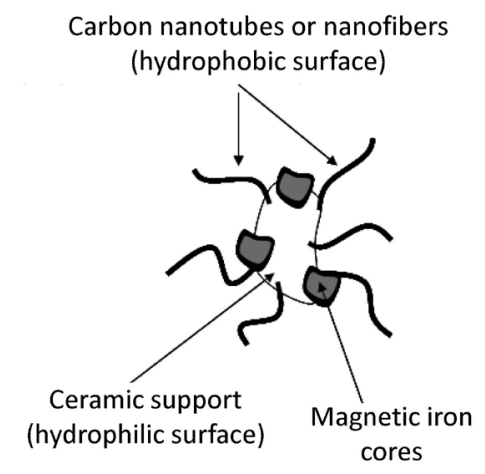

Figure 14. Representation of the magnetic amphiphilic composites (adapted from reference 45).

For the synthesis of these composites, a matrix containing Fe catalyst was submitted to CVD to grow carbon nanostructures, mainly nanofibers (NF) and nanotubes (NT). ${ }^{49,50}$ 


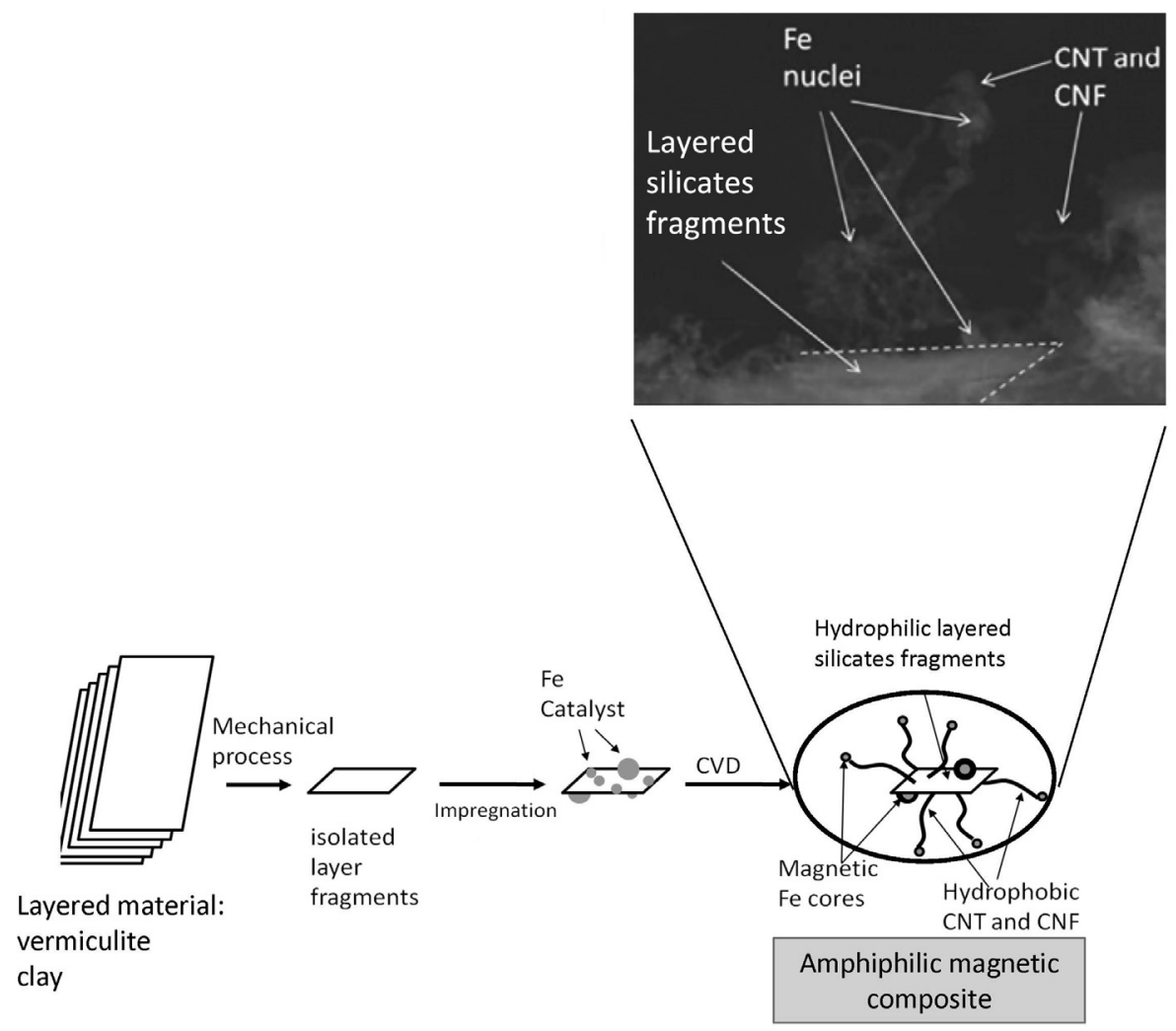

Figure 15. Representation of impregnation and synthesis of magnetic amphiphilic composites based on vermiculite/iron/carbon (adapted from reference 55).

The control of the type and amount of carbon formed is important for the different envisaged applications of the composites. Our group has reported works using different ceramic matrices, such as alumina, ${ }^{51,52}$ vermiculite ${ }^{46,47,53,54}$ and chrysotile minerals ${ }^{46,48}$ magnesia ${ }^{55}$ and peroviskites. ${ }^{39,52}$

Microparticles of magnetic amphiphilic composites were produced from the clay vermiculite. The lamellar clay mineral was first fragmented to form microsheet fragments. The microsheets were then impregnated with iron nitrate and subjected to a CVD process to grow the carbon nanostructures $\mathrm{s}^{46,47,53,54}$ (Figure 15).

Similar approach was used to prepare magnetic amphiphilic composites with the fibrous mineral chrysotile. ${ }^{46,48}$ Figure 16 shows SEM images of a crysotile/ carbon nanostructure/iron core composite.

\section{Emsulsifier and demulfier}

A very promising application for the amphiphilic materials is the formation and breaking of emulsions (Figure 17) with several potential uses in different industries, such as petrochemistry, biodiesel, vegetable oils and wastewater treatment. ${ }^{56-58}$ Due to the amphiphilic character of these materials, they act in the interface of the droplets. Figure 17 shows an optic microscopy image of an oil-water emulsion stabilized by amphiphilic magnetic material.
Our group has reported the utilization of magnetic amphiphilic composites in different steps of biodiesel production. ${ }^{46}$ For example, in the transesterification reaction to produce biodiesel, oils do not mix with the alkali/ methanol phase and a vigorous stirring to promote a good interface is necessary for the reaction to take place. ${ }^{59}$ When the amphiphilic composites were added to these biphasic systems, an emulsion was formed and due to the excellent interface, an efficient transesterification took place. ${ }^{46}$

After transesterification, the biodiesel is emulsified with a more polar phase reaction formed by water, glycerol and the excess methanol. Due to the magnetic properties of the amphiphilic composites, they can be dragged towards an external applied magnetic field.

This magnetic process destabilizes the emulsion leading to a rapid phase separation schematically represented in Figure 18. Furthermore, amphiphilic materials have also proved effective to break the emulsion formed during washing and the wastewater from the production of

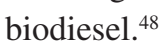

Adsorption of hazardous large hydrophobic contaminant molecules

Amphiphilic materials can be used as a highly efficient adsorbent for hazardous organic contaminant molecules 


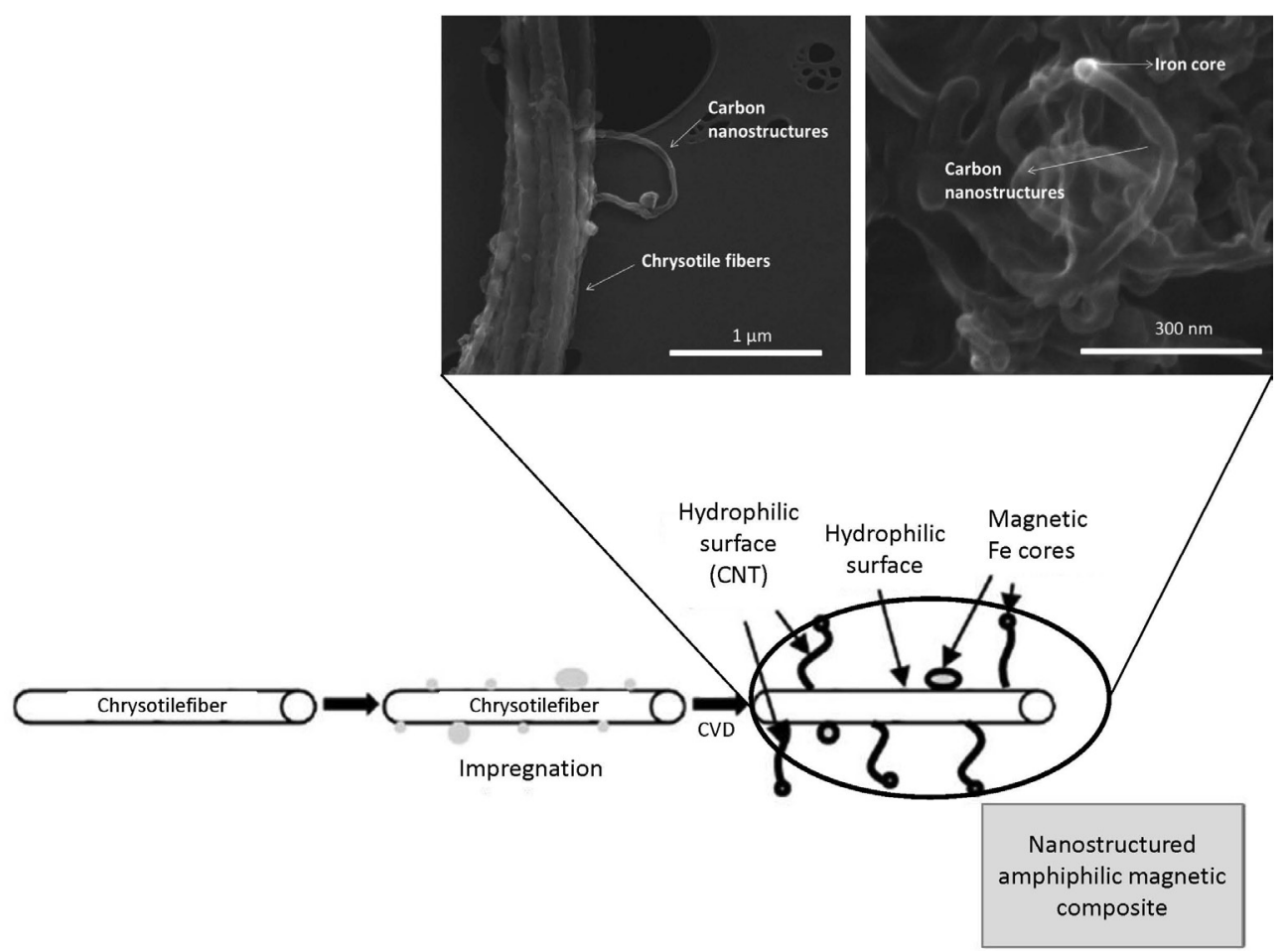

Figure 16. Representation of impregnation and synthesis of magnetic amphiphilic composites based on chrysotile/iron/carbon (adapted from reference 55).

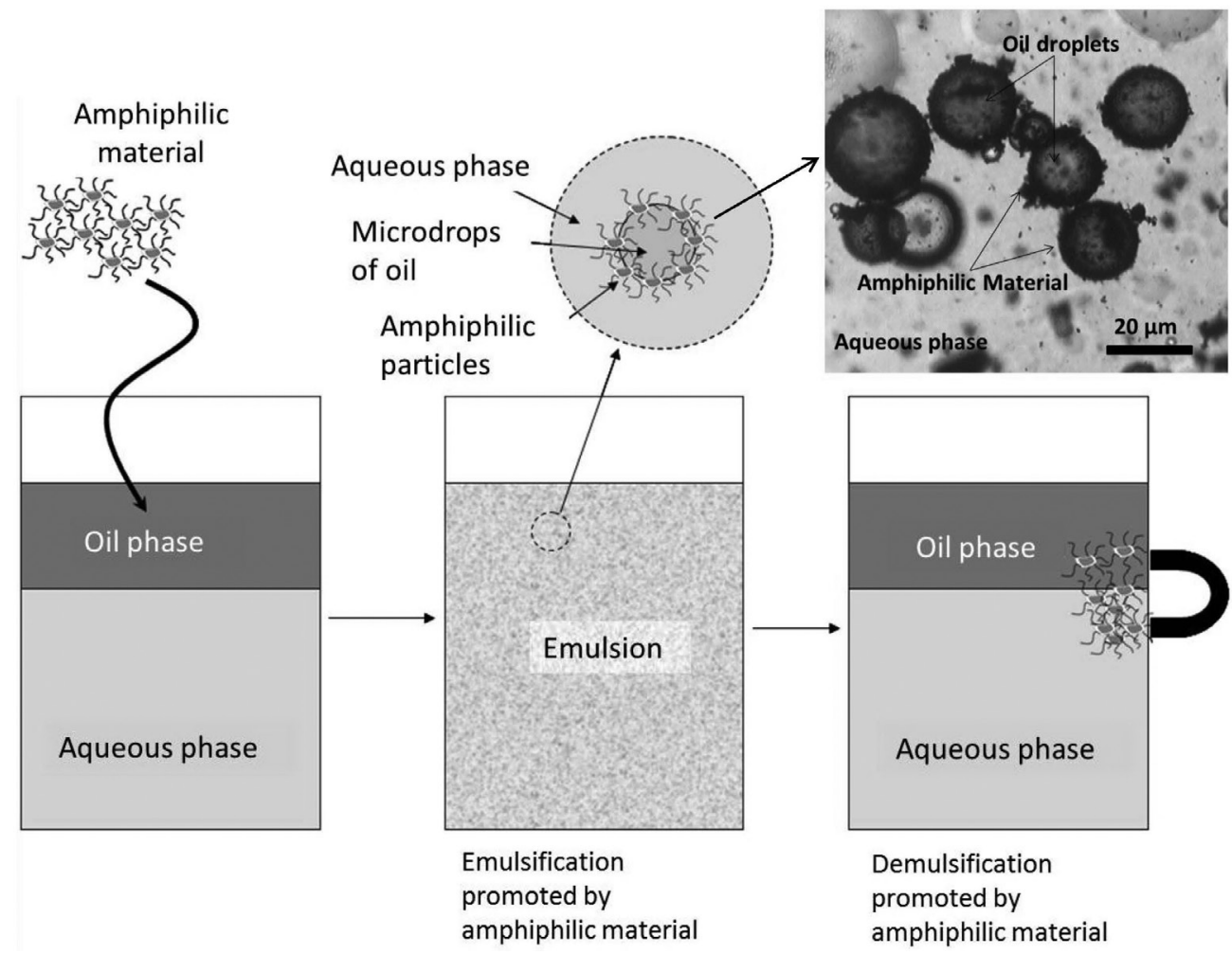

Figure 17. Scheme of emulsion formation promoted by magnetic hybrid materials.

in wastewaters such as endocrinous disruptor. The carbon nanostructures (nanotubes and nanofibers (CNF)) of the amphiphilic materials supported on the inorganic surface are very efficient for the adsorption of these hydrophobic organic molecules. Our group showed that the composite formed by the inorganic support vermiculite, carbon nanostructures and magnetic iron particles were effective for the adsorption of the hormone ethinylestradiol in water. ${ }^{47}$ 


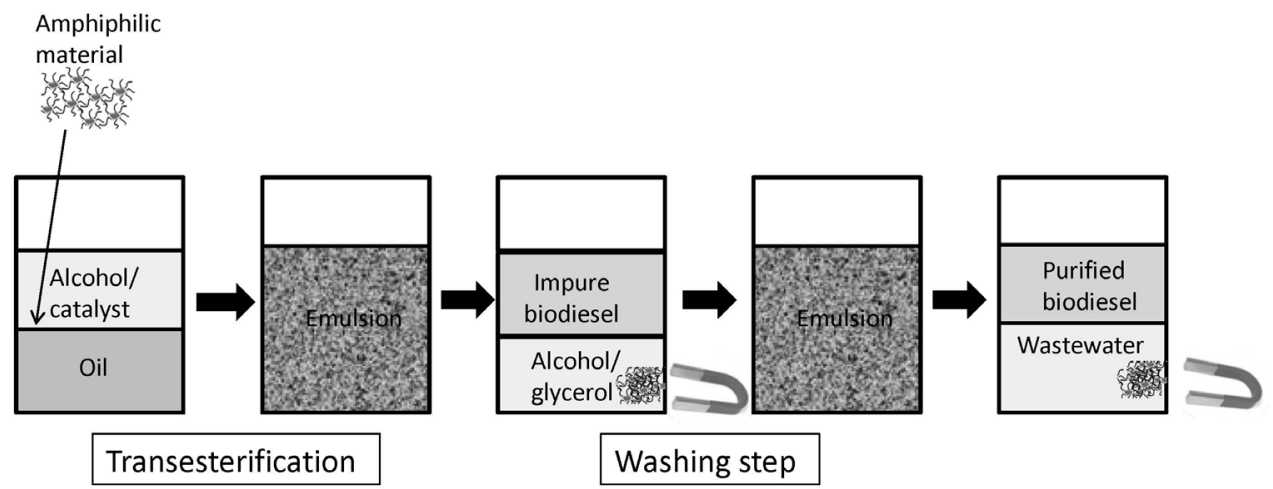

Figure 18. Scheme of biodiesel synthesis using amphiphilic materials (adapted from reference 55).

Due to the presence of the inorganic support, the composite disperses very well in water while keeping the CNT and CNF separated (avoiding agglomeration). This exposed carbon surface area is very efficient for the adsorption of the hormone (Figure 19). Furthermore, the presence of magnetic iron phases allows a facile magnetic separation of the composite from the medium after adsorption.

\section{Catalytic Applications of Iron Based Materials}

Iron phases can be used as catalysts for different reactions, especially oxidations of contaminants such as $\mathrm{CO},{ }^{60} \beta$-pinene ${ }^{61}$ and toluene. ${ }^{62,63}$ Magnetite showed a high activity for the oxidation of carbon monoxide at lower temperatures, being related to the presence of surface $\mathrm{Fe}^{2+}$ species capable of activating gas phase $\mathrm{O}_{2}$ to form more reactive species..$^{64,65}$

Magnetite doped with $\mathrm{Mn}$ or $\mathrm{Co}, \mathrm{Fe}_{3-\mathrm{x}} \mathrm{M}_{\mathrm{x}} \mathrm{O}_{4}(\mathrm{M}=\mathrm{Mn}$, $\mathrm{Co} ; \mathrm{x}=0-0.75)$ was also used as catalyst to high selective oxidation of $\beta$-pinene, a renewable monoterpene, under solvent free conditions. The pinene is oxidized with $\mathrm{O}_{2}$ with high selectivity to special products for the perfume and flavor industries. ${ }^{61}$

The introduction of $\mathrm{Fe}$ in the $\mathrm{LaMnO}_{3}$ structure produced oxidation catalysts with improved properties. The presence of small amounts of $\mathrm{Fe}$ in the perovskite structure led to an increase of the catalytic activity for the oxidation of VOCs such as methane and toluene. The improvement of the catalytic activity was discussed in terms of the effect of $\mathrm{Fe}$ on the creation of surface and structural defects which can increase the perovskite reactivity towards oxygen. . $33,65^{2}$

Iron was also used as catalyst associated with materials such as clays. The pillared clay montmorillonite containing highly dispersed iron oxide showed very good activity and stability for the oxidation of toluene. ${ }^{62}$

\section{Fuel Storage}

Hydrogen is considered the most promising fuel to replace fossil energy sources. ${ }^{66}$ However, the large-scale
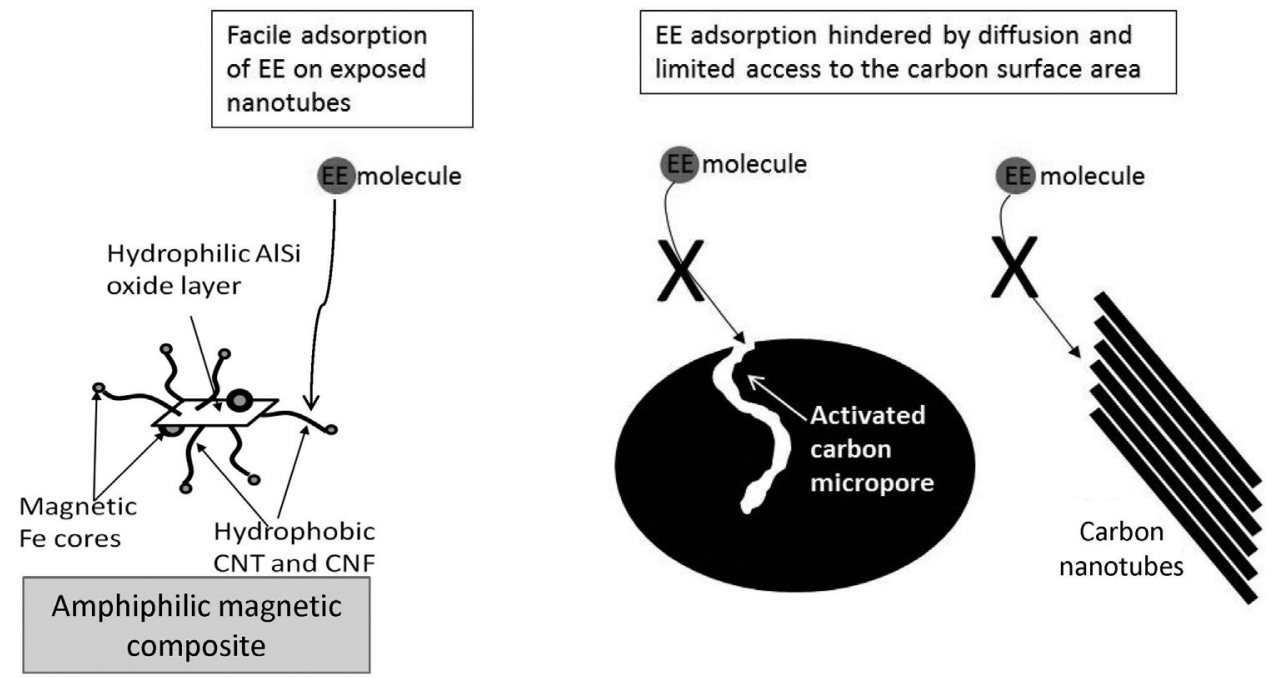

Figure 19. Scheme comparing the adsorption of EE on the vermiculite composite, activated carbon and carbon nanotube bundles (adapted from reference 47). 
use of $\mathrm{H}_{2}$ faces two main challenges: the production and storage. ${ }^{67}$ The main production methods that have been studied are electrolysis, ${ }^{68}$ thermolysis ${ }^{69}$ water photolysis,${ }^{70}$ biological process ${ }^{71}$ and reforming of methane or alcohols. ${ }^{72}$ The use of ethanol for the production of hydrogen has been considered an interesting route since ethanol is a renewable fuel, easy to transport with low toxicity. ${ }^{73}$ Our group has developed a new concept based on a redox cycle for $\mathrm{H}_{2}$ production and storage using ethanol and iron compounds. This process occurs in two steps. First, ethanol reduces the iron ion phases to iron metal. Second, $\mathrm{H}_{2}$ is produced by the oxidation of the iron metal with water. An advantage of this process is the indirect storage of hydrogen. The iron metal obtained in the first part of the cycle can be stored and transported to produce $\mathrm{H}_{2}$ wherever it is necessary by a reaction with $\mathrm{H}_{2} \mathrm{O}$ (Figure 20).

Different iron compounds were studied, e.g., $\mathrm{Ni}_{\mathrm{x}} \mathrm{Fe}_{3-\mathrm{x}} \mathrm{O}_{4}$ ferrites, ${ }^{74}$ goethite, hematite and magnetite, ${ }^{75}$ and $\mathrm{Fe}_{2} \mathrm{O}_{3}$ supported in $\mathrm{SiO}_{2}$ or $\mathrm{Al}_{2} \mathrm{O}_{3}{ }^{76} \mathrm{All}$ iron based system showed promising results for $\mathrm{H}_{2}$ storage.

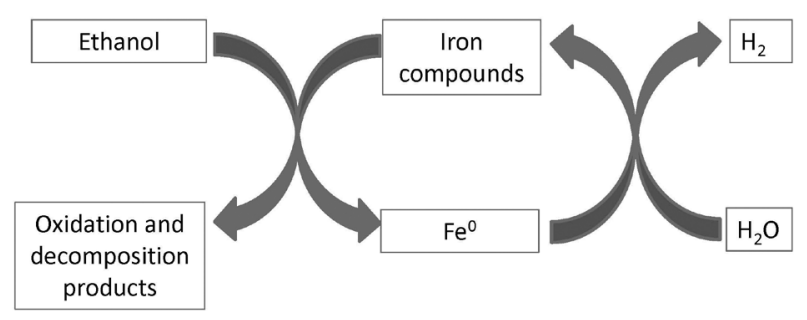

Figure 20. Hydrogen production redox cycle using ethanol and iron compounds (adapted from reference 76).

\section{Use of Iron Containing Wastes for Environmental Applications}

Several industries produce large amounts of Fe rich wastes such red mud (RM, produced in the Bayer process), foundry sand, kaolin mining and blast furnace dust waste from the steel industry. ${ }^{75}$ The Fe present in these wastes in relatively high concentrations can be used for several environmental applications as described in some of the work carried out in our group (Figure 21).
$\mathrm{RM}$ is an iron rich waste of the $\mathrm{Al}_{2} \mathrm{O}_{3}$ extraction by the Bayer process. It is mainly composed of $\mathrm{Fe}_{2} \mathrm{O}_{3}$ (ca. 20-30 wt.\%), $\mathrm{Al}_{2} \mathrm{O}_{3}, \mathrm{CaO}, \mathrm{SiO}_{2}$ and $\mathrm{TiO}_{2}{ }^{76}$ Red mud can be reduced by $\mathrm{H}_{2}$ to produce different iron phases from $\mathrm{Fe}_{3} \mathrm{O}_{4}$, $\mathrm{Fe}_{3} \mathrm{O}_{4} / \mathrm{Fe}^{0}$ to pure $\mathrm{Fe}^{0}$. The other oxides present in RM, such as $\mathrm{Al}_{2} \mathrm{O}_{3}$ and $\mathrm{SiO}_{2}$, are thermally stable and act as support to disperse the iron phases improving their reactivity. The obtained materials showed very good results for the oxidation of organic contaminants in water using $\mathrm{H}_{2} \mathrm{O}_{2}$ in a Fenton like reaction. ${ }^{77}$ These composites also showed good activity for $\mathrm{Cr}(\mathrm{VI})$ reduction. ${ }^{77}$ Red mud can also be used for the upgrading of bio-oil which involves mainly deoxygenation reactions promoted by reduced iron species. ${ }^{78}$

Waste foundry sand (WFS) contains silica sand, clay binder, carbon and iron mainly present as oxide and metal. The texture and granulometry of WFS make it a suitable candidate to produce reactive permeable barriers. ${ }^{79}$

WFS and blast furnace dust are not active for environmental processes. However, after a simple thermal treatment, these wastes strongly increased the activity for different reactions, such as Fenton oxidation and $\mathrm{Cr}(\mathrm{VI})$ reduction. ${ }^{80}$

These results were discussed in terms of reactions of the carbon present in the waste to reduce the different iron species to form active reducing iron phases (equation 3 ).

$\mathrm{Fe}_{2} \mathrm{O}_{3} / \mathrm{C}$ (waste) $\rightarrow \mathrm{Fe}_{3} \mathrm{O}_{4} \rightarrow \mathrm{FeO} \rightarrow \mathrm{Fe}^{0}\left(\mathrm{~N}_{2}\right.$ atmosphere $)$

Kaolin is a material extensively used in the paper industry. The kaolin mining produces large amounts of a waste composed of $\mathrm{TiO}_{2}$ phases, $\mathrm{Fe}$ oxides/oxyhydroxides and quartz. The controlled reduction of the kaolin waste with $\mathrm{H}_{2}$ at $400{ }^{\circ} \mathrm{C}$ produced efficient systems for the oxidation of different contaminants with aqueous $\mathrm{H}_{2} \mathrm{O}_{2}$ and also for the $\mathrm{Cr}(\mathrm{VI})$ reduction. ${ }^{81}$

RM can also be used as catalyst for the CVD synthesis of the carbon nanostructures from ethanol as carbon source. Figure 22 shows carbon nanostructures and iron cores obtained after CVD synthesis with RM.

The obtained magnetic composites showed very good results as adsorbent for dyes in aqueous medium and

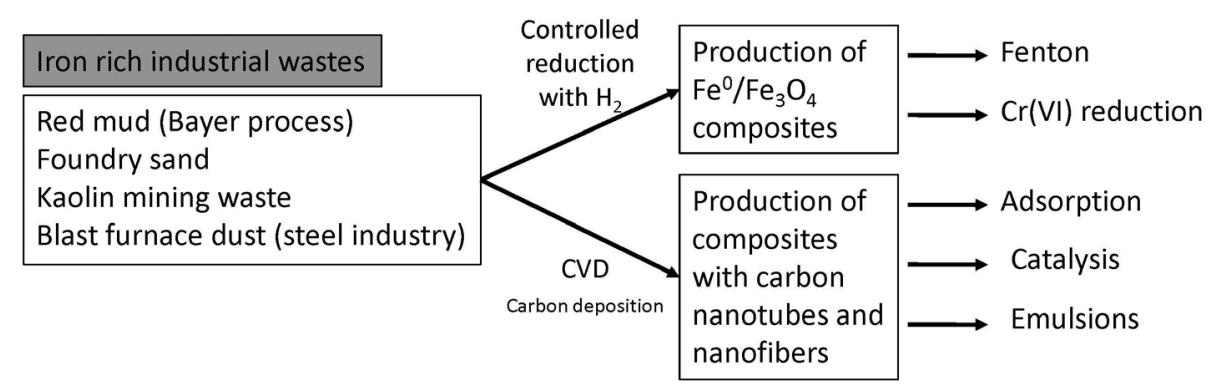

Figure 21. Iron rich wastes and modification processes for environmental applications. 

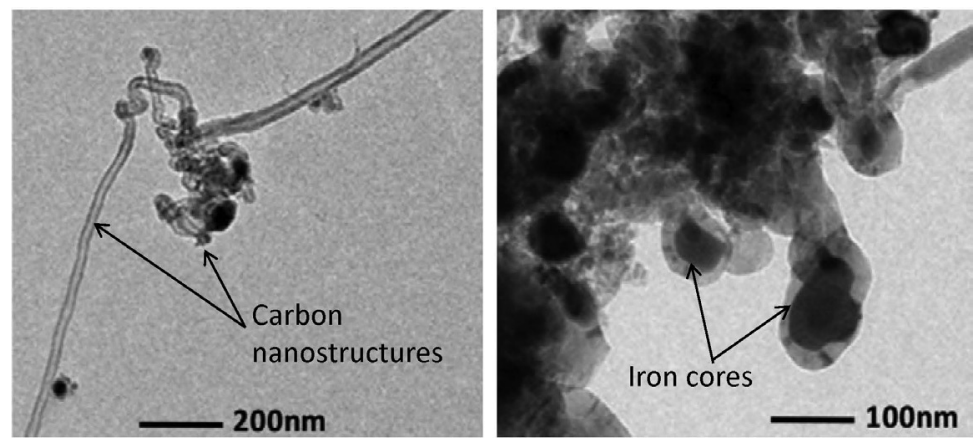

Figure 22. TEM images of magnetic composites based in red mud (adapted from reference 42).

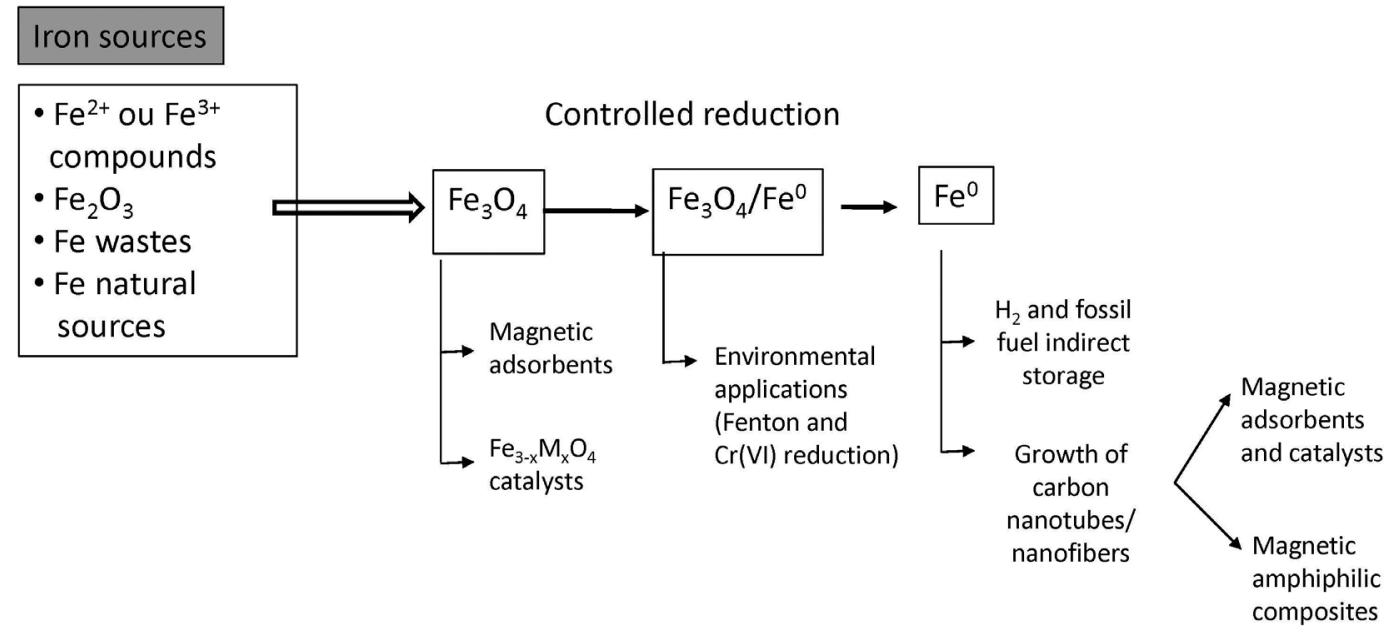

Figure 23. Scheme of controlled reduction and application of different Fe sources.

as support to produce greener recyclable magnetic Pd catalyst using the model reaction of 1,5-cyclooctadiene hydrogenation.

\section{Conclusions}

Iron is very versatile element. It can be reversibly transformed in different phases with remarkable physicochemical properties and many potential technological applications. Figure 23 shows some possible applications of iron phases. The controlled reduction of different $\mathrm{Fe}$ sources, $\mathrm{Fe}^{2+}, \mathrm{Fe}^{3+}$, iron oxides and hydroxides and iron rich wastes and natural sources produces $\mathrm{Fe}_{3} \mathrm{O}_{4}, \mathrm{Fe}^{0}$ and $\mathrm{Fe}^{0} / \mathrm{Fe}_{3} \mathrm{O}_{4}$ composites (Figure 23). The inverse spinel $\mathrm{Fe}_{3} \mathrm{O}_{4}$ is magnetic and can be combined with different materials to produce magnetic adsorbents. It can also be used as catalyst, especially when Fe is replaced in the structure by other metals such as $\mathrm{Co}, \mathrm{Mn}$ and $\mathrm{Cr}$. The composites $\mathrm{Fe}^{0} / \mathrm{Fe}_{3} \mathrm{O}_{4}$ showed remarkable activity as electron transfer systems which can be used in many environmental applications such as the Fenton reaction and $\mathrm{Cr}(\mathrm{VI})$ reduction. Fe metal can be used for $\mathrm{H}_{2}$ and fossil fuel storage carbon nanotubes and nanofiber growth to produce magnetic composites with application as adsorbent, catalyst support and amphiphilic materials for emulsions.

\section{Acknowledgements}

The authors thank Conselho Nacional de Desenvolvimento Científico e Tecnológico (CNPq), Fundação de Amparo à Pesquisa do estado de Minas Gerais (FAPEMIG), Coordenação de Aperfeiçoamento de Pessoal de Nível Superior (CAPES), PRPq-UFMG and Centro de Microscopia (UFMG).

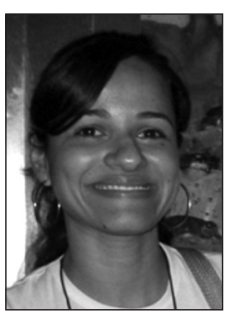

Ana Paula de Carvalho Teixeira is graduated in Chemistry at Universidade Federal de Minas Gerais (UFMG, Minas Gerais State, Brazil) and obtained her MSc degree at Centro de Desenvolvimento da Tecnologia Nuclear (Minas Gerais State, Brazil). She obtained her PhD at UFMG working on the preparation of amphiphilic magnetic composites and carbon nanotubes for application in synthesis, catalysis and environmental processes. 


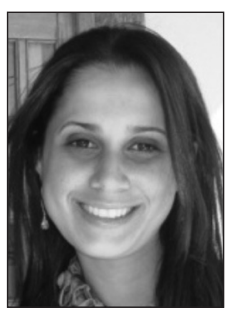

Juliana Cristina Tristão is graduated and obtained her PhD in Chemistry at Universidade Federal de Minas Gerais (UFMG, Minas Gerais State, Brazil). She is currently a professor at Universidade Federal de Viçosa (UFV Minas Gerais State, Brazil) developing research on the synthesis and application of magnetic particles based on iron and carbon nanostructures for application in environmental processes and heterogeneous catalysis.

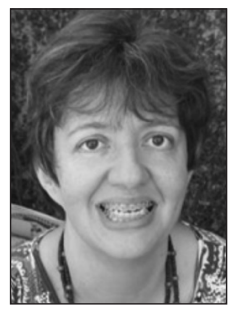

Maria Helena Araujo obtained her MSc under the supervision of Prof Maria D. Vargas at Universidade de Campinas (UNICAMP, São Paulo State, Brazil) in 1990 and the PhD in 1995 at UNICAMP and Sussex University (United Kingdon) under the supervision of Prof Maria D. Vargas and John F. Nixon. This was followed by a research fellow position at Sussex University from 1996-1997 and a Postdoctoral position at UNICAMP from 1998-1999, working always with organometallic chemistry. Since 2000 she is working at Department of Chemistry at Universidade Federal de Minas Gerais (UFMG, Minas Gerais State, Brazil) on environmental chemistry and catalysis. She is currently working with magnetic nanoparticles covered with carbon and ionic liquids for catalysis.

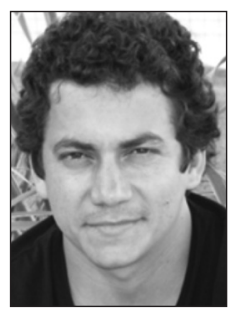

Luiz Carlos A. Oliveira has graduated in Chemistry, BSc (1997), Master in Physical Chemistry (2000) and PhD in Inorganic Chemistry at Universidade Federal de Minas Gerais (UFMG, Minas Gerais State, Brazil) and Post doctorate at University of California (USA, 2009). He is currently an adjunct professor at UFMG and member of the Advisory Board of the CEX-Fapemig. He operates in environmental chemistry, on the following subjects: activated charcoal, iron oxide, catalysis, adsorption and contaminants. He was a fellow of Productivity and Technological Development Innovative Extension.

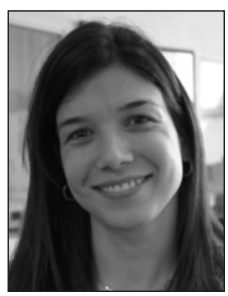

Flávia Cristina Camilo Moura has graduated and obtained her PhD in Chemistry at Universidade Federal de Minas Gerais (UFMG, Minas Gerais State, Brazil) In 2005 she spent one year at University of Montreal
(Canada) under the supervision of Prof Richard Martel working with carbon nanotubes. Since 2009 she works at Department of Chemistry (UFMG) developing research on heterogeneous catalysis and adsorbents with environmental applications.

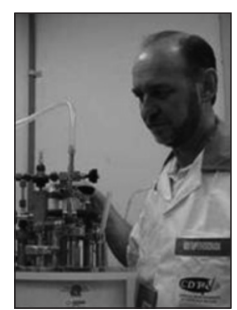

José Domingos Ardisson has graduated in Physics at Universidade Federal do Espírito Santo (Espírito Santo State, Brazil) in 1982 and MSc and PhD in Physics at Universidade Federal de Minas Gerais (UFMG, Minas Gerais State, Brazil) (1995). Since 1998 he is a researcher at the Applied Physics Laboratory, Nuclear Technology Development Center (CDTN/CNEN Minas Gerais State, Brazil).

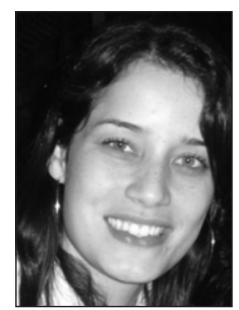

Camila Costa de Amorim graduated in Environmental Engineering at Universidade Federal de Viçosa (UFV, Minas Gerais State, Brazil) has PhD in Sanitation, Environment and Water Resources at Universidade Federal de Minas Gerais (Minas Gerais State). She is currently Adjunct Professor in the Department of Sanitary and Environmental Engineering in UFMG, developing research on wastewater treatment technologies and industrial waste reuse, with emphasis in advanced oxidative process and developing of the iron oxides catalysts for environmental applications.

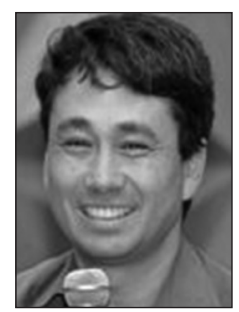

Rochel Montero Lago is graduated at Universidade de Campinas (UNICAMP, São Paulo State, Brazil) with MSc under the supervision of Prof Ulf Schuchardt. In 1992, he spent one year at Gifu University (Japan) followed by a PhD at Oxford University (United Kingdom) under the supervision of Prof M. L. H. Green and a Pos-Doc with Prof J. L. G Fierro at Institute of Catalysis and Petrochemistry (Madrid, Spain) working always in the area of catalysis. In 2005, he went to University of Montreal (Canada) as a Visiting Researcher at the laboratories of Prof Richard Martel to work with carbon nanotubes and a Pos-Doc at the business school HEC (Heutes Etudes Commerciales, Canada) with Prof L. J. Filion on the theme technological entrepreneurship. He works at Department of Chemistry at Universidade Federal de Minas Gerais (UFMG, Minas Gerais State, Brazil) since 1997. 


\section{References}

1. Cornell R. W.; Schwertmann, U.; The Iron Oxides, $1^{\text {st }}$, WileyVCH: New York, 1996.

2. Lemley, A. T.; Wang, Q.; Saltmiras, D. A. In Pesticide Decontamination and Detoxification, ACS Symposium Series, No. 863; Gan, J. J.; Zhu, P. C.; Aust, S. D.; Lemley, A. T., eds.; Oxford University Press: USA, 2003, p. 65-83.

3. Moura, F. C. C.; Oliveira, G. C.; Araujo, M. H.; Ardisson, J. D.; Macedo, W. A. A.; Lago, R. M.; Appl. Catal., A 2006, 307, 195.

4. Huang, H. H.; Lu, M.C.; Chen, J. N.; Water Res. 2001, 35, 2291.

5. Centi, G.; Perathoner, S.; Torre, T.; Verduna, M. G.; Catal. Today 2000, 55, 61 .

6. Kwan, W. P.; Voelker, B. M.; Environ. Sci. Technol. 2003, 37, 1150.

7. Kwan, W. P.; Voelker, B. M.; Environ. Sci. Technol. 2002, 36, 1467.

8. Chou, S.; Huang, C.; Chemosphere 1999, 38, 2719.

9. Feng, J.; Hu, X.; Yue, H. Y.; Zhu, Y.; Lu, G. Q.; Water Res. 2003, 37, 3776.

10. Friák, M.; Schindlmayr, A.; Scheffler, M.; New J. Phys. 2007, 9, 5 .

11. Costa, R. C. C.; Lelis, M. F. F.; Oliveira, L. C. A.; Fabris, J. D.; Ardisson, J. D.; Rios, R. R. V. A.; Silva, C. N.; Lago, R. M.; Catal. Commun. 2003, 4, 525.

12. Costa, R. C. C.; Lelis, M. F. F.; Oliveira, L. C. A.; Fabris, J. D.; Ardisson, J. D.; Rios, R. R. V. A.; Silva, C. N.; Lago, R. M.; J. Hazard. Mater. 2006, B129, 171.

13. Costa, R. C. C.; Moura, F. C. C.; Ardisson, J. D.; Fabris, J. D.; Lago, R. M.; Appl. Catal., B Environ. 2008, 83, 131.

14. Coelho, F.; Ardison, J. D.; Moura, F. C. C.; Lago, R. M.; Murad, E.; Fabris, J. D.; Chemosphere 2008, 71, 90.

15. Moura, F. C. C.; Araujo, M. H.; Costa, R. C. C.; Fabris, J. D.; Ardisson, J. D.; Macedo, W. A. A.; Lago, R. M.; Chemosphere 2005, 60, 1118.

16. Moura, F. C. C.; Araujo, M. H.; Dalmázio, I.; Alves, T. M. A.; Santos, L. S.; Eberlin, M. N.; Augusti, Rodinei ; Lago, R. M.; Rapid Commun. Mass Spectrom. 2006, 20, 1859.

17. Magalhães, F.; Moura, F. C. C.; Ardisson, J. D.; Lago, R. M.; Mater. Res. 2008, 11, 307.

18. Moura, F. C. C.; Araújo, M. H.; Ardisson, J. D.; Macedo, W. A. A.; Albuquerque, A. S.; Lago, R. M.; J. Braz. Chem. Soc. 2007, 18, 322.

19. Callao, M. P.; Gómes, V.; TrAC, Trends Anal. Chem. 2006, 25 , 1006.

20. Park, J. M.; Park, D.; Yun, Y. S.; J. Colloid Interface Sci. 2008, 317, 54.

21. Fendorf, S.; Ginder-Vogel, M.; Borch, T.; Mayes, M. A.; Jardine, P. M.; Environ. Sci. Technol. 2005, 39, 7833.

22. Lee, D. Y.; Yu, P. F.; Juang, K. W.; Plant Soil 2004, 258, 333.
23. Pereira, M. C.; Coelho, F. S.; Nascentes, C. C.; Fabris, J. D.; Araújo, M. H.; Sapag, K.; Oliveira, L. C. A.; Lago, R. M.; Chemosphere 2010, 81, 7.

24. Magalhães, F.; Pereira, M. C.; Fabris, J. D.; Bottrel, S. E. C.; Sansiviero, M. T. C.; Amaya, A.; Tancredi, N.; Lago, R. M.; J. Hazard. Mater. 2009, 165, 1016.

25. Booker, N. A.; Keir, D.; Priestley, A.; Rithchie, C. D.; Sudarmana, D. L.; Woods, M. A.; Water Sci. Technol. 1991, 23,1703 .

26. Safarik, I.; Safarikova, M.; Buricova, V.; Collect. Czech. Chem. Commun. 1995, 60, 1448.

27. Orbell, J. D.; Godhino, L.; Bigger, S. W.; Nguyen, T. M.; Ngeh, L. N.; J. Chem. Educ. 1997, 74, 1446.

28. Shim, J. W.; Park, S. J.; Ryu, S. K.; Carbon 2001, 39, 1635.

29. Oliveira, L. C. A.; Rios, R. V. R. A.; Fabris, J. D.; Garg, V.; Sapag, K.; Lago, R. M.; Carbon 2002, 40, 2177.

30. Oliveira, L. C. A.; Rios, R. V. R. A.; Fabris, J. D.; Lago, R. M.; Sapag, K.; J. Chem. Educ. 2004, 81, 248.

31. Pignon, H.; Brasquet, C.; La Cloirec, P.; Water Sci. Technol. 2000, 42, 355.

32. Lua, A. C.; Guo, J.; J. Environ. Eng. 2001, 127, 889.

33. Oliveira, L. C. A.; Rios, R. V. R. A.; Fabris, J. D.; Sapag, K.; Garg, V. K.; Lago, R. M.; Appl. Clay Sci. 2003, 22, 169.

34. Martins, J.; Br 39004025, 1990.

35. Machado, L. C. R.; Torchia, C. B.; Lago, R. M.; Catal. Comum. 2006, 7, 538.

36. Machado, L. C. R.; Lima, F. W. J.; Paniago, R.; Ardison, J. D.; Sapag, K.; Lago, R. M.; Appl. Clay Sci. 2006, 31, 207.

37. Zhao, X. L.; Shi, Y. L.; Wang, T.; Cai, Y. Q.; Jiang, G. B.; J. Chromatogr., A 2008, 1188, 140.

38. Lee, J.; Lee, Y.; Youn, J. K.; Bin Na, H.; Yu, T.; Kim, H.; Lee, S. M.; Koo, Y. M.; Kwak, J. H.; Park, H. G.; Chang, H. N.; Hwang, M.; Park, J. G.; Kim, J.; Hyeon, T.; Small 2008, 4, 143.

39. Moura, F. C. C.; Tristão, J. C.; Lago, R. M.; Martel, R.; Catal. Today 2008, 133, 846.

40. Tristão, J. C.; Oliveira, A. A. S.; Ardisson, J. D.; Dias, A.; Lago, R. M.; Mater. Res. Bull. 2011, 46, 748.

41. Tristão, J. C.; Silva, A. A.; Ardisson, J. D.; Lago, R. M.; Hyperfine Interact. 2010, 195, 21.

42. Oliveira, A. A. S.; Tristão, J. C.; Ardisson, J. D.; Dias, A.; Lago, R. M.; Appl. Catal., B 2011, 105, 163.

43. Tristão, J. C.; Ardisson, J. D.; Sansiviero, M. T. C.; Lago, R. M.; Hyperfine Interact. 2010, 195, 15.

44. Mendonça, F. G.; Ardisson, J. D.; Rosmaninho, M. G.; Lago, R. M.; Tristão, J. C.; Hyperfine Interact. 2011, 202, 123.

45. Oliveira, A. S.; Teixeira, F. T.; Ribeiro, L. P.; Tristão, J. C.; Dias, A. D.; Lago, R. M.; J. Braz. Chem. Soc. 2010, 21, 2184.

46. Teixeira, A. P. C.; Purceno, A. D.; Barros, A. S.; Lemos, B. R. S.; Ardisson, J. D.; Macedo, W. A. A.; Nassor, E. C. O.; Amorim, C. C.; Moura, F. C. C.; Hernández-Terrones, M. G.; Portela, F. M.; Lago, R. M.; Catal. Today 2012, 190, 133. 
47. Purceno, A. D.; Teixeira, A, P. C.; de Souza, N. J.; Fernandez-Outon, L. E.; Ardisson, J. D.; Lago, R. M.; J. Colloid Interface Sci. 2012, 379, 84.

48. Lemos, B. R. S.; Teixeira, A. P. C.; Ardisson, J. D.; Macedo, W. A. A.; Fernandez-Outon, L. E.; Amorim, C. C.; Moura, F. C. C.; Lago, R. M.; Appl. Sci. 2012, 2, 513.

49. Oncel, C.; Yurum, Y.; Fullerenes, Nanotubes, Carbon Nanostruct. 2006, 14, 17.

50. Dupuis, A. C.; Prog. Mater. Sci. 2005, 50, 929.

51. Oliveira, P. F.; Ribeiro, L. P.; Rosmaninho, M. G.; Ardisson, J. D.; Dias, A.; Lago, R. M.; Hyperfine Interact. 2011, 203, 67.

52. Tristão, J. C.; Moura, F. C. C.; Lago, R. M.; Sapag, K.; Quim. Nova 2010, 33, 1379.

53. Moura, F. C. C.; Lago, R. M.; Appl. Catal., B 2009, 90, 436.

54. Purceno, A. D.; Barrioni, B. R.; Dias, A.; Costa, G. M.; Lago, R. M.; Moura, F. C. C.; Appl. Clay Sci. 2011, 54, 15.

55. Teixeira, A. P. C.; Lemos, B. R. S.; Magalhães, L. A.; Ardisson, J. D.; Lago, R. M.; Furtado, C. A.; Santos, A. P.; J. Nanosci. Nanotechnol. 2012, 12, 2661.

56. Barros, F. F. C.; Quadros, C. P.; Maróstica Jr., M. R.; Pastore, G. M.; Quim. Nova 2007, 30, 409.

57. Al-Sabagh, A. M.; Maysour, N. E.; NoorEl-Din, M. R.; J. Dispersion Sci. Technol. 2007, 28, 547.

58. Oliveira, A. G.; Scarpa, M. V.; Correa, M. A.; Cera, L. F. R.; Formariz, T. P.; Quim. Nova 2004, 27, 131.

59. Sharma, Y. C.; Singh, B.; Korstad, J.; Fuel 2011, 90, 1309.

60. Oliveira, L. C. A.; Fabris, J. D.; Rios, R. R. V. A.; Mussel, W. N.; Lago, R. M.; Appl. Catal., A 2004, 259, 253.

61. Menini, L.; da Silva, M. C.; Lelis, M. F. F.; Fabris, J. D.; Lago, R. M.; Gusevskaya, E. V.; Appl. Catal., A 2004, 269, 117.

62. Nogueira, F. G. E.; Lopes, J. H.; Silva, A. C.; Lago, R. M.; Fabris, J. D.; Oliveira, L. C. A.; Appl. Clay Sci. 2011, 51, 385.

63. Tristão, J. C.; Ardisson, J. D.; Macedo, W. A. A.; Lago, R. M.; Moura, F. C. C.; J. Braz. Chem. Soc. 2007, 18, 1524.

64. Lelis, M. F. F.; Rios, R. V. R. A.; Lago, R. M.; Fabris, J. D.; Mussel, W. N.; Macedo, W. A. A.; Martins, M. D.; Hyperfine Interact. 2002, 5, 345.

65. Rosmaninho, M. G.; Tristão, J. C.; Moura, F. C. C.; Lago, R. M.; Araujo, M. H.; Anal. Bioanal. Chem. 2010, 396, 2785.

66. Navarro, R. M.; Alvarez-Galvan, M. C.; Villoria, J. A.; Al-Zahrani, S. M.; Fierro, J. L. G.; Energy Environ. Sci. 2010, 3,1865 .
67. Wendt, W.; Götz, M.; Linardi, M.; Quim. Nova 2000, 23, 538.

68. Sigurvinsson, J.; Mansilla, C.; Lovera, P.; Werkoff, F.; Int. J. Hydrogen Energy 2007, 32, 1174.

69. Steinfeld, A.; Sol. Energy 2005, 78, 603.

70. Yan, J. H.; Zhu, Y. R.; Tang, Y. G.; Zheng, S. Q.; J. Alloys Compd. 2009, 472, 429.

71. Levin, D. B.; Chahine, R.; Int. J. Hydrogen Energy. 2010, 35, 4962.

72. Armos, J. N.; Catal. Lett. 2005, 101, 131.

73. Hotza, D.; da Costa, J. C. D.; Int. J. Hydrogen. Energy 2008 , 33, 4915.

74. Rosmaninho, M. G.; Herreras, S.; Lago, R. M.; Araujo, M. H.; Navarro, R. M.; Fierro, J. L. G.; Nanosci. Nanotechnol. Lett. 2011, 3, 705 .

75. Rosmaninho, M. G.; Moura, F. C. C.; Souza, L. R.; Nogueira, R. K.; Gomes, G. M.; Nascimento, J. S.; Pereira, M. C.; Fabris, J. D.; Ardisson, J. D.; Nazarro, M. S.; Sapag, K.; Araujo, M. H.; Lago, R. M.; Appl. Catal., B 2012, 115, 45.

76. Rosmaninho, M. G.; Souza, L. R.; Gomes, G. M.; Zica, R. F.; Nascimento, J. S.; Pereira, M. C.; Fabris, J. D.; Ardisson, J. D.; Moura, F. C. C.; Lago, R. M.; Araujo, M. H.; Hyperfine Interact. 2010, 195, 49.

75. Dungan, R.; Dees, N.; Water Air Soil Pollut. 2007, 183, 213.

76. Power, G.; Grafe, M.; Klauber, C.; Hydrometallurgy 2011, 108, 33.

77. Costa, R. C. C.; Moura, F. C. C.; Oliveira, P. E. F.; Magalhaes, F.; Ardisson, J. D.; Lago, R. M.; Chemosphere 2010, 78, 1116.

78. Karimi, E.; Teixeira, I. F.; Ribeiro, L. P.; Gomez, A.; Lago, R. M.; Penner, G.; Kycia, S. W.; Schlaf, M.; Catal. Today 2012, 190, 73.

79. Oliveira, P. E. F.; Oliveira, L. D.; Ardisson, J. D.; Lago, R. M.; J. Hazard. Mater. 2011, 194, 393.

80. Amorim, C. C.; Dutra, P. R.; Pereira, M. C.; Fabris, J. D.; Lago, R. M.; Chem. Eng. J. 2012, in press, DOI: 2012.08.023.

81. Pereira,M.C.; Tavares, C.M.; Fabris, J.D.; Lago, R. M.; Murad,E.; Criscuolo, P. S.; Clay Miner. 2007, 42, 299.

Submitted: August 22, 2012 Published online: September 21, 2012 